\title{
Projeto e implementação de ensaio de fadiga por tração-compressão direta (uniaxial) para avaliação de dano em misturas asfálticas
}

\author{
Design and implementation of direct tension- \\ compression fatigue testing apparatus for \\ damage evaluation in hot mix asphalt
}

\author{
Fernando Dekeper Boeira ${ }^{1}$, Gustavo dos Santos Pinheiro ${ }^{1}$, Luciano Pivoto Specht ${ }^{1}$, \\ Eduardo Londero Druzian ${ }^{1}$, Mauro Lichtenecker Just ${ }^{1}$, \\ Lucas Feitosa de Albuquerque Lima Babadopulos', \\ Luis Alberto Herrmann do Nascimento ${ }^{3}$, \\ Deividi da Silva Pereira ${ }^{1}$
}

\footnotetext{
${ }^{1}$ Grupo de Estudos e Pesquisas em Pavimentação e Segurança Viária, LMCC/CT/UFSM, Santa Maria, RS, Brasil e-mail: fernando.d.boeira@gmail.com; gustavo.snt@ hotmail.com; luspecht@ufsm.br; eduardo-druzian@hotmail.com; maurojust@terra.com.br; dsp@ufsm.br

${ }^{2}$ Laboratório de Mecânica dos Pavimentos da Universidade Federal do Ceará (LMP/UFC), Fortaleza, CE, Brasil. e-mail: lucasbaba@det.ufc.br

${ }^{3}$ Centro de Pesquisa e Desenvolvimento Leopoldo Américo Miguez de Mello, Petrobras, Rio de Janeiro, RJ, Brasil. e-mail: luisnascimento@petrobras.com.br
}

\begin{abstract}
RESUMO
No país, são dois os mais recorrentes defeitos encontrados nas rodovias: deformação permanente e trincamento por fadiga. Dentre as mais variadas causas, a formação e propagação de trincas no revestimento asfáltico ocorrem em consequência das repetidas solicitações do tráfego que, com o tempo, reduzirão drasticamente a vida de serviço do pavimento, por exemplo, facilitando a penetração de água nas camadas granulares da estrutura e acelerando sua deterioração. Além disso, os ensaios mais comumente utilizados no Brasil para avaliação e previsão de desempenho quanto à fadiga do concreto asfáltico ainda suscitam muitos questionamentos no meio técnico-científico. Assim, no contexto da caracterização avançada de misturas asfálticas, realizou-se o desenvolvimento de projetos referentes a um sistema mecânico para ensaio bem como de tratamento de dados após os testes. Trata-se do ensaio de Fadiga por Tração-Compressão Direta (Uniaxial) que possibilita avaliar e caracterizar o comportamento de misturas asfálticas quanto ao dano por fadiga. Foram realizadas adaptações de peças já existentes em outros dois centros de pesquisa para que se ajustassem à prensa hidráulica utilizada na Universidade Federal de Santa Maria (UFSM): a Universal Testing Machine (UTM-25). Testes foram efetuados e monitorados para certificar a compatibilidade entre as peças produzidas e a prensa hidráulica utilizada e os resultados encontrados demonstraram sucesso no caminho proposto.
\end{abstract}

Palavras-chave: Pavimentação asfáltica. Fadiga por Tração-Compressão Direta (Uniaxial). Aparato de ensaio.

\begin{abstract}
In the country, there are two most common distress found on highways: rutting and fatigue cracking. Through the most varied causes, the formation and propagation of cracks occurs as a result of repeated traffic demands and over time will drastically reduce the service life of the pavement, for example, facilitating ingress of water in granular layers of the structure and accelerating its deterioration. In addition, the most commonly used methods in Brazil for assessing and predicting fatigue behavior of asphalt concrete raises many questions to the scientific and technical community. Thus, in the context of Hot Mix Asphalt (HMA) advanced characterization, projects of the apparatus were developed as well the data processing. It is the Direct Tension Cyclic Fatigue Test to evaluate and characterize HMA behavior when it comes to fatigue damage. Adaptations of existing parts from two other research centers were made in to fit the hydraulic press used in Universidade Federal de Santa Maria (UFSM): the Universal Testing Machine (UTM-25). Tests were
\end{abstract}


performed to verify the compatibility between pieces produced and hydraulic press, which demonstrated success in this matter.

Keywords: Asphalt paving. Direct Tension Fatigue. Test apparatus.

\section{INTRODUÇÃO}

O bom desempenho dos revestimentos asfálticos depende de procedimentos corretos no projeto, da escolha adequada dos materiais e da formulação das proporções ou misturas que atendam às condicionantes de uso. Posteriormente ao projeto, esse desempenho dependerá de técnicas adequadas de produção, distribuição e execução das camadas asfálticas no pavimento, importante nas rodovias brasileiras com volume de tráfego entre médio e alto, dispondo do Concreto Asfáltico (CA) como revestimento, e que tem sido extensivamente estudado, tanto individualmente - ligantes e agregados - quanto em mistura, de maneira a atender à crescente demanda de durabilidade, aliada à escassez de recursos do setor rodoviário.

BERNUCCI et al. [1] afirma que devido ao vasto uso do modo rodoviário, aliado ao crescente aumento da frota e ao excesso de cargas transportadas, há um comprometimento do desempenho dos pavimentos asfálticos, o que favorece à ocorrência de deteriorações prematuras e, consequentemente, gerando o aumento no custo operacional. A degradação dos pavimentos asfálticos brasileiros se intensifica por se tratar de um país com clima tropical, em que na maior parte do ano, as temperaturas são elevadas.

Os principais defeitos encontrados nas rodovias brasileiras são as deformações permanentes em trilha de rodas e os trincamentos por fadiga, relacionados diretamente com o tráfego atuante, estrutura do pavimento/mistura e condições climáticas. Esses defeitos frequentemente ocorrem precocemente, prejudicando a trafegabilidade, a segurança viária, além de danificar a estrutura dos pavimentos. Segundo BASTOS et al. [2], a deformação permanente provoca os afundamentos nas trilhas de roda, afundamentos localizados e corrugações nos revestimentos, dificultando a drenagem da água e aumentando o risco de hidroplanagem. Já, para NASCIMENTO [3], o trincamento por fadiga é proveniente dos efeitos cumulativos causados pela repetição de cargas e dos consequentes deslocamentos, resultando na redução da durabilidade do revestimento. $\mathrm{O}$ aparecimento de trincas facilita a penetração de água nas camadas granulares do pavimento, acelerando sua deterioração.

O fenômeno de fadiga é de natureza complexa, e está relacionado tanto às características estruturais, quanto de materiais nos pavimentos revestidos por concreto asfáltico, além do clima. Atualmente, no Brasil, os ensaios disponíveis (por exemplo, o ensaio de fadiga por compressão diametral) e protocolos de análises tem suscitado questionamentos quando empregados na previsão do desempenho à fadiga de misturas asfálticas.

Os primeiros pesquisadores, em âmbito internacional, a relacionar as trincas nos pavimentos revestidos por concreto asfáltico com carregamento cíclico causado pelo tráfego foram PORTER [4] em 1942, NIJBOER e VAN DER POEL [5] em 1953, HVEEM [6] em 1955 e MOAVENZADEH [7] em 1971. Já, no Brasil, o estudo em laboratório sobre a vida de fadiga em misturas asfálticas foi apresentado por PREUSSLER et al. [8] em 1981, no qual os autores apresentavam os primeiros modelos de fadiga de concretos asfálticos, em que era esboçado um exemplo de aplicação dos resultados dos ensaios no projeto de reforço de uma estrutura de pavimento, introduzindo de maneira pioneira no país um estudo sobre tal mecanismo de ruptura.

O ensaio de compressão diametral (tração indireta) foi criado pelo brasileiro Fernando Lobo Carneiro, em 1943, para determinação da resistência à tração de concretos de cimento Portland. O mesmo foi adaptado para o uso de cargas repetidas (ensaio de fadiga) e para aplicação em misturas asfálticas. Para o ensaio de fadiga por compressão diametral, com norma ainda em desenvolvimento pelo Departamento Nacional de Infraestrutura de Transportes (DNIT), são utilizados corpos de prova cilíndricos carregados por compressão na direção vertical, o que produz uma tensão de tração na direção horizontal da amostra. O carregamento se dá pela frequência de 60 aplicações por minuto, com um pulso de carga de $0,1 \mathrm{~s}$ seguido de $0,9 \mathrm{~s}$ de repouso. A amostra é submetida a um estado biaxial de tensões $[9,10]$.

Esse ensaio, conduzido à tensão controlada, é o mais utilizado no país para estimar a vida de fadiga, porém, apesar da facilidade de obtenção das amostras (de $63 \mathrm{~mm}$ de altura e $102 \mathrm{~mm}$ de diâmetro), o mesmo apresenta fatores que dificultam a caracterização do comportamento à fadiga quando comparado a um ensaio cíclico de tração-compressão. São apresentados, na Figura 1, esquemas comparativos das possíveis solicitações impostas e as respostas de ensaios de fadiga. Na Figura 1d, nota-se que, à medida que o material é submetido a um regime de tensão controlada, originam-se deformações permanentes e, por não ser possível desassociar o dano à fadiga do dano causado por essas deformações, o teste por compressão diametral acaba sendo de difícil interpretação e não representativo da fadiga do material [11,12]. Além de ser um ensaio que 
demanda muito tempo de operação.

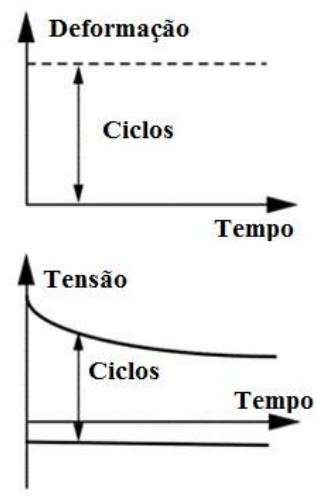

a)
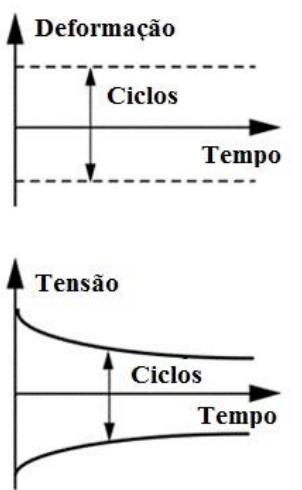

b)
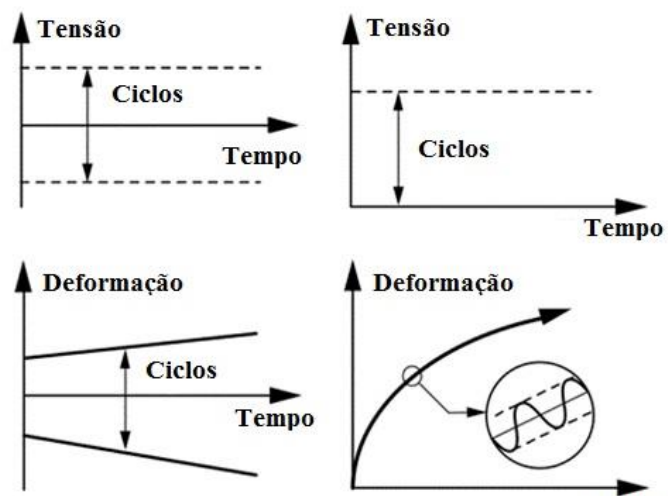

c)

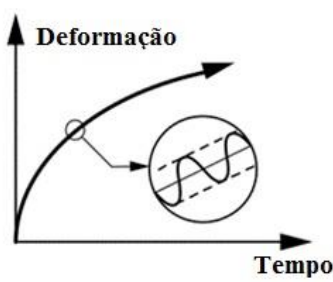

d)

Figura 1: Esquema de representação de carregamento, deformação (a e b) ou tensão (c e d), e respectiva resposta, em tensão ou deformação [12].

As normas AASHTO T 321-07 [13] e ASTM D 7460-08 [14] descrevem o ensaio de fadiga de 4 pontos de vigas de misturas asfálticas, no Brasil ainda não se dispõe de uma norma para esse ensaio. As normas definem o parâmetro de rigidez à flexão da viga como sendo a relação entre a tensão máxima de tração e a deformação máxima da viga. A frequência estabelecida em normas para o ensaio é de $5 \mathrm{~Hz}$ a $10 \mathrm{~Hz}$ e temperatura de $20^{\circ} \mathrm{C}$, entretanto, os equipamentos permitem a variação destes parâmetros de ensaio para uma análise mais profunda do comportamento do material asfáltico. Para a realização do ensaio, necessita-se de um aparato servo-hidráulico capaz de aplicar cargas senoidais (tração/compressão) com frequência variável de $0,01 \mathrm{~Hz}$ a $30 \mathrm{~Hz}$. As vigotas utilizadas como corpos de prova para ensaio de fadiga devem possuir comprimento de $380 \pm 6 \mathrm{~mm}$, largura de $63 \pm 6 \mathrm{~mm}$ e altura de $50 \pm 6 \mathrm{~mm}$, e em função de seu formato, sua execução se torna mais difícil quando comparada a de outros ensaios. DI BENEDETTO et al. [15] discutem diferentes formas de ensaios de fadiga, bem como abordagens de interpretação.

Recentemente foi desenvolvido pela equipe da North Carolina State University (NCSU), nos Estados Unidos, um novo tipo de ensaio para previsão da vida de fadiga em misturas asfálticas, que considera propriedades fundamentais para caracterização efetiva de seu comportamento. Na execução do ensaio são coletados e monitorados os sinais de deformação e de carga, a partir dos quais se medem duas propriedades dos materiais: o ângulo de fase (defasagem dos sinais senoidais de tensão e deformação) e o módulo dinâmico (razão entre as amplitudes de tensão e deformação).

O ensaio de Fadiga por Tração-Compressão Direta (Uniaxial) consiste na aplicação de uma deformação cíclica senoidal de amplitude constante na amostra, avaliando-se a evolução da rigidez do material até que ocorra a ruptura, que pode ser detectada pela evolução do ângulo de fase. Seus resultados são modelados de acordo com a mecânica do dano contínuo, através do modelo Simplified Viscoelastic Continuum Damage (S-VECD), proposto por UNDERWOOD e KIM [16], a fim de estabelecer a vida de fadiga das misturas asfálticas, independentemente da condição de carregamento, com um menor número de amostras e menos tempo de execução quando comparado aos outros ensaios de fadiga, segundo MARTINS [17].

Ademais, através realização do novo ensaio de fadiga, é possível a implementação do modelo SVECD num programa computacional, nomeado Layered Viscoelastic Pavement Analysis for Critical Distresses (LVECD), para análise de pavimentos asfálticos. Esse framework já foi implementado e validado no Brasil por meio da comparação extensiva entre o desempenho observado em campo e previsto nas análises computacionais, utilizando integralmente materiais e pavimentos brasileiros, conforme NASCIMENTO [3].

O presente trabalho tem o intuito de apresentar a implantação e o desenvolvimento do ensaio de Fadiga por Tração-Compressão Direta (Uniaxial) no Laboratório de Materiais de Construção Civil (LMCC) da Universidade Federal de Santa Maria (UFSM), contribuindo para a compreensão do dano por fadiga no âmbito nacional, possibilitando que outros centros de pesquisa utilizem está ferramenta. Visa ainda demonstra a forma de interpretação de resultados e obtenção de parâmetros característicos dos material. 


\section{MATERIAIS E MÉTODOS}

No Brasil, desde a década de 1980, é uma prática muito comum utilizar o ensaio de compressão diametral de carga repetida com tensão controlada para definir as curvas características de fadiga em misturas asfálticas de uma mesma temperatura e frequência, principalmente no meio acadêmico. Contudo, estudos desenvolvidos ao longo de duas décadas por pesquisadores liderados pelo professor Y. Richard Kim, da NCU, propuseram uma nova técnica para a determinação da vida de fadiga, onde é possível obter curvas experimentais por tração direta e com interpretação teórica mais consistente, segundo NASCIMENTO et al. [18].

O ensaio de Fadiga por Tração-Compressão Direta (Uniaxial) segue as prescrições da norma AASHTO TP 107-14 [19] e consiste em aplicar uma deformação cíclica senoidal de amplitude constante em uma amostra cilíndrica até que ocorra a ruptura ou a defasagem do ângulo de fase. Na realização do ensaio são coletados e monitorados deformação, carga, ângulo de fase e módulo dinâmico.

Na Universidade Federal de Santa Maria (UFSM), para executar o ensaio, utiliza-se a prensa hidráulica Universal Testing Machine (UTM - 25) da IPC Global, esquematizada na Figura 2, dispõe de uma célula de carga de $\pm 25 \mathrm{kN}$, uma cabine com controle de temperatura e, ainda, um sistema de controle e aquisição de dados, denominado IMACS (Integrated Multi-Axis Control System), conectado a um microcomputador. Para a execução do ensaio, fez-se necessário a fabricação de peças para a adaptação na UTM-25, a fim de proporcionar carregamentos de tração-compressão nos corpos de prova.

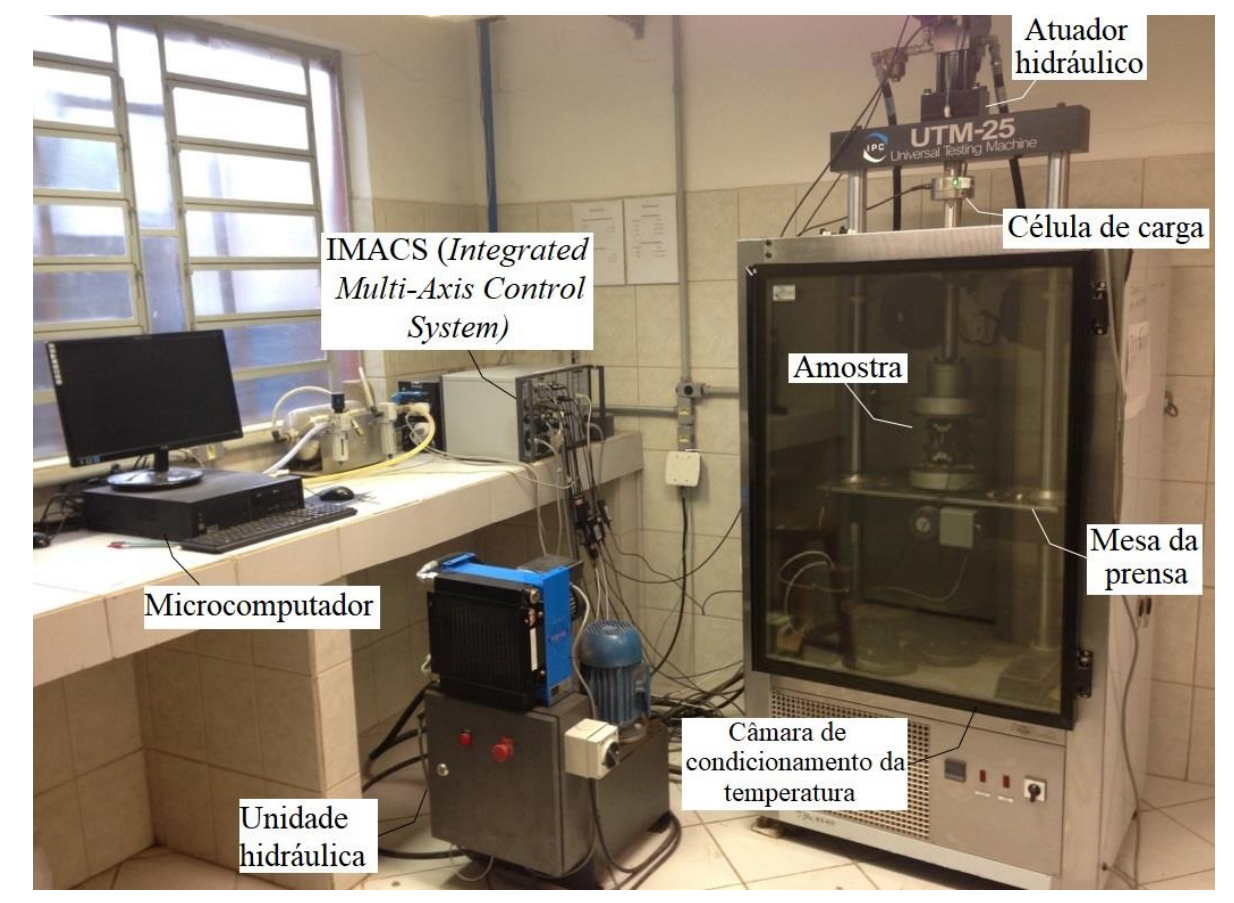

Figura 2: Prensa hidráulica, UTM-25, da Universidade Federal de Santa Maria (UFSM).

\subsection{Projetos e execução das peças}

Para a confecção das peças, realizou-se primeiramente uma pesquisa dos principais centros que executam o ensaio no Brasil. Constatou-se que o Centro de Pesquisas e Desenvolvimento Leopoldo Américo Miguez de Mello (Cenpes), localizado na Cidade Universitária, campus da Universidade Federal do Rio de Janeiro (UFRJ), e o Laboratório de Mecânica dos Pavimentos da Universidade Federal do Ceará (UFC) realizam o ensaio de Fadiga por Tração-Compressão Direta (Uniaxial).

Em ambos os centros, foram realizadas visitas acadêmicas, instruindo-se melhor sobre o ensaio, para que então fossem realizados os projetos de adaptação das peças e, em seguida, a execução do ensaio no Laboratório de Materiais de Construção Civil da UFSM.

Para a produção das peças, foram realizados cerca de oito projetos, que contemplaram todas as adaptações das peças para a execução do ensaio na UTM-25, assim como o sistema de colagem dos corpos de prova. Os projetos foram realizados utilizando uma conjunção entre as adaptações dos centros (Cenpes e UFC), ou seja, foram realizadas adaptações no sistema de colagem das peças nos corpos de prova e no aparato de fixação na prensa. Os projetos na integra estão disponíveis nos apêndices da tese de doutorado de BOEIRA [20]. As peças que atendem aos projetos são: sistemas de acoplagem à prensa UTM-25, rótula, placas 
cilíndricas de colagem dos corpos de prova e todo o sistema para realização da colagem das placas. A rotulagem do atuador hidráulico da UTM-25 com a amostra, é ilustrada na Figura 3.

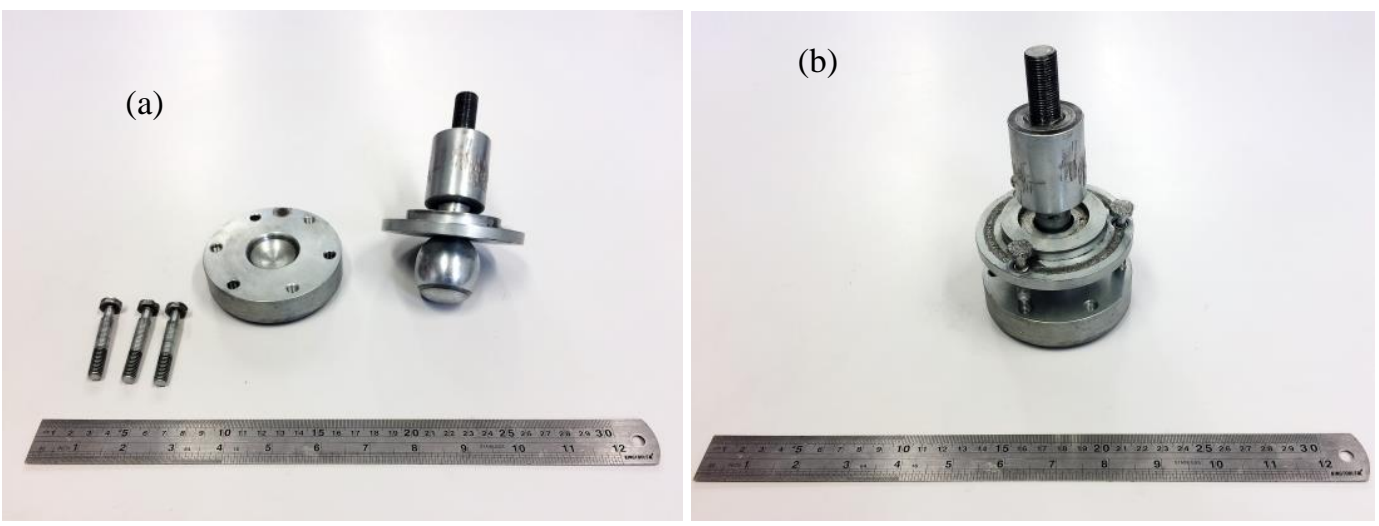

Figura 3: Sistema de rotulagem (a) desmontado e (b) montado.

O sistema de rotulagem é formado por dois suportes que se encaixam a uma rótula conectada ao atuador hidráulico da UTM-25, essa rótula é encarregada pelo ajuste correto do posicionamento do sistema de rotulagem em relação à amostra. Os demais aparatos de fixação do corpo de prova com a prensa, conforme é ilustrado nas Figuras 4 e 5, foram elaborados a partir de adaptações fundamentadas no sistema do Cenpes.
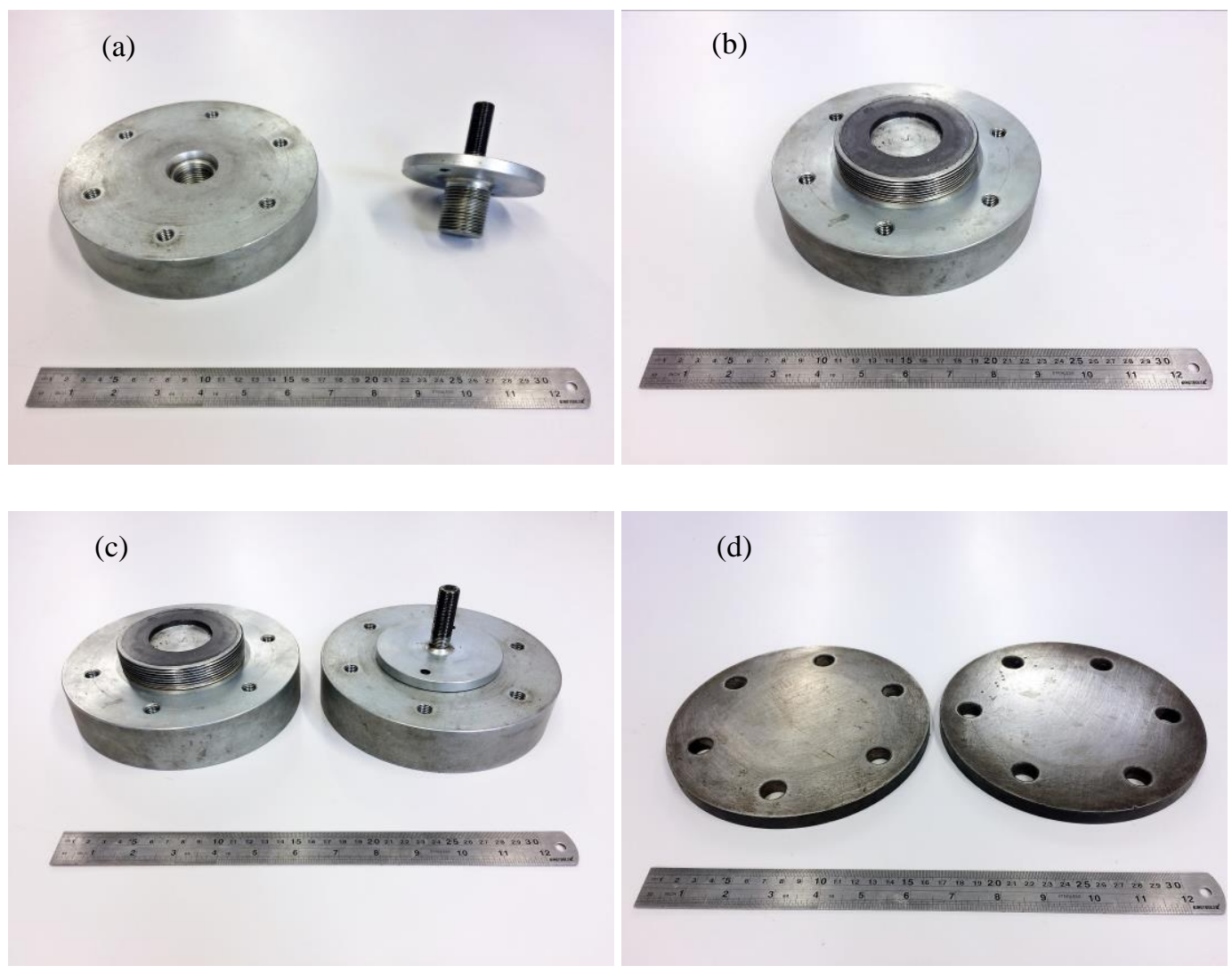

Figura 4: (a) Placa suporte inferior, (b) placa suporte superior, (c) placas de suporte e (d) placas de colagem.

As placas de suportes superior e inferior são espessas chapas metálicas, dimensionadas com $40 \mathrm{~mm}$ de espessura e 190 mm de diâmetro, e projetadas para resistir aos esforços de tração-compressão aplicados durante o ensaio mecânico. A placa de suporte inferior, na Figura 4a, conecta-se diretamente à mesa da prensa UTM-25, enquanto a placa de suporte superior, na Figura 4b, faz parte da ligação entre o sistema de rotulagem e a amostra a ser ensaiada. Já a Figura 4d expõe as placas de colagem top-down, de dimensões $12 \times 190$ 
mm, que são coladas nas faces superior e inferior dos corpos de prova.

Para que haja vinculação entre o sistema de rotulagem e a amostra já colada às chapas, confeccionouse o copo de acoplagem da rótula, mostrado na Figura 5, pois ele irá englobar todo o sistema de rotulagem e será rosqueado à chapa de suporte superior.

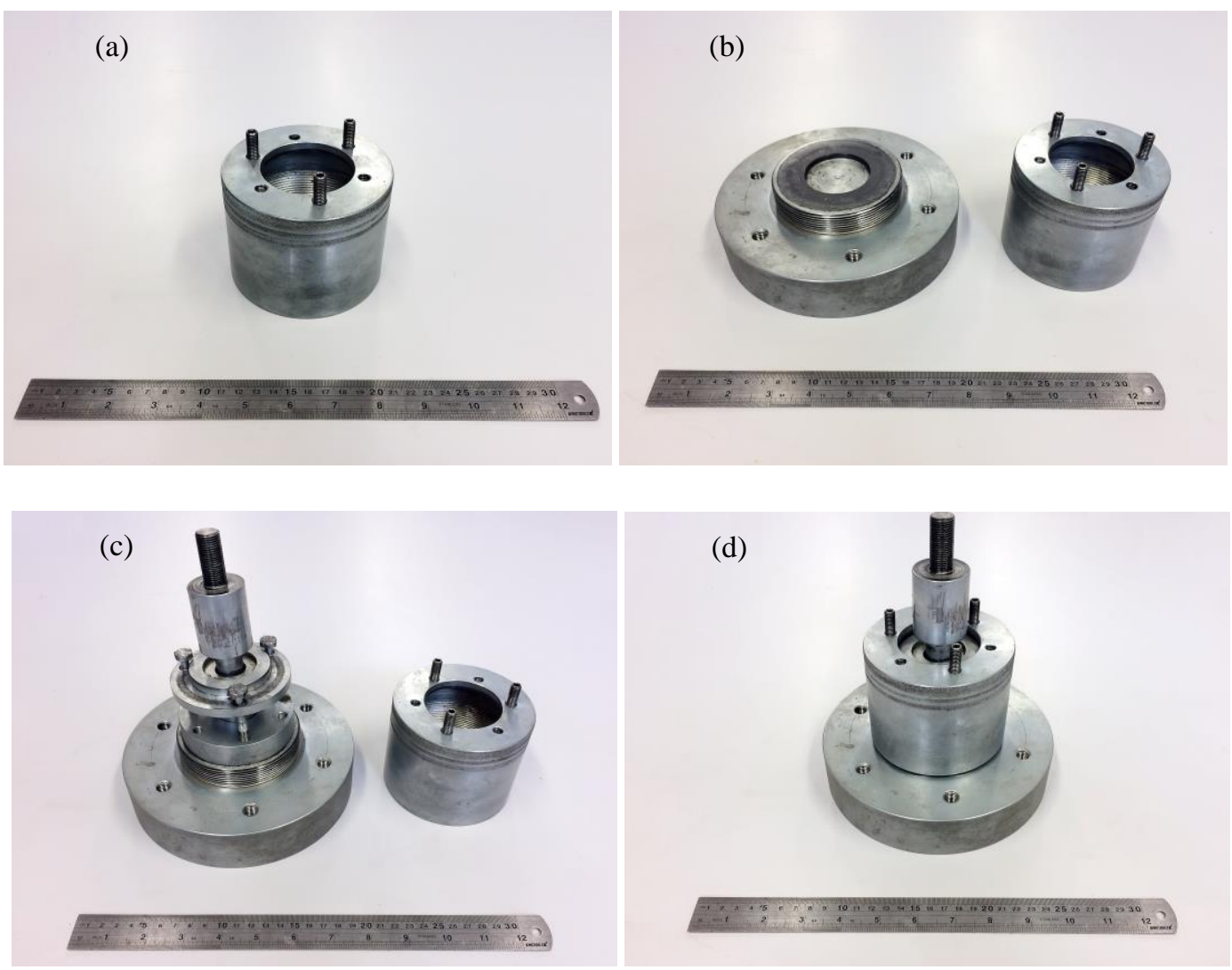

Figura 5: Copo para acoplagem do sistema de rotulagem em sequência de montagem (a, b, c e d) das peças com a placa suporte superior.

O sistema para suporte de colagem dos corpos de prova, representado na Figura 6a, consiste em uma base metálica retangular que sustenta duas placas fixadas em suas extremidades e uma placa móvel entre elas, conforme Figura 6b. Posicionadas perpendicularmente à base, as placas são ligadas por quatro hastes que garantirão o alinhamento das peças no momento da colagem. Para possibilitar a mobilidade do sistema, uma manivela foi fixada à placa móvel. Além disso, criou-se um suporte para os corpos de prova. Esse suporte, também fixado à base do sistema de colagem, no qual sustenta as amostras durante o processo de fixação e, por possuir roscas em suas extremidades, detalhadas na Figura 6c, permite que a estrutura seja movida verticalmente no momento da colagem e propicie um melhor alinhamento entre o centro das chapas cilíndricas e a amostra. 


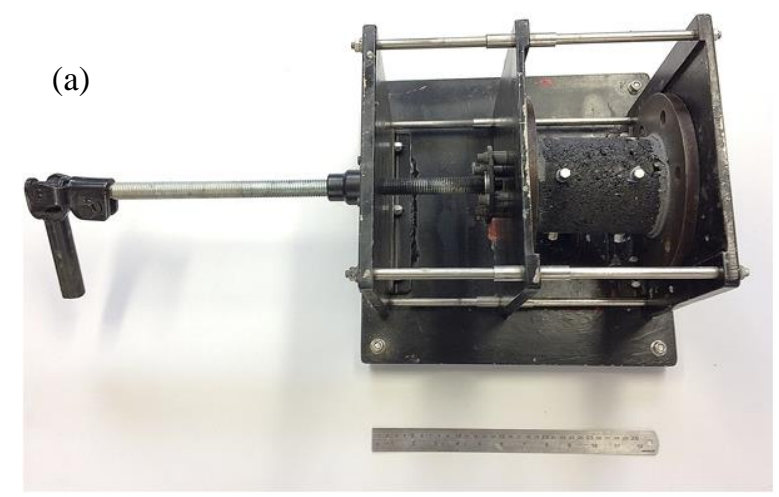

(b)

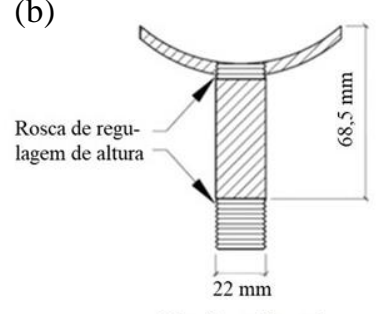

Vista frontal (corte)

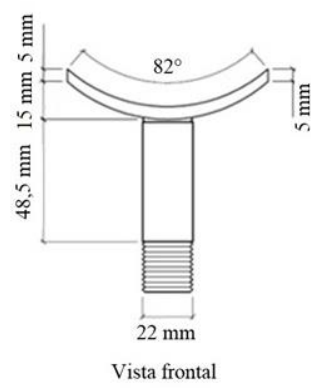

Figura 6: (a) Sistema de colagem da amostra e placas de colagem e (b) detalhamento do suporte da amostra no sistema de colagem.

\subsection{Preparação e execução do ensaio de Fadiga por Tração-Compressão Direta (Uniaxial)}

As amostras testadas foram compostas por agregados de origem vulcânica (Diabásio) e Cimento Asfáltico de Petróleo 50/70, enquadradas na Faixa granulométrica "C", conforme DNIT 031/2006 - ES [21], e moldadas no Compactador Giratório Superpave (CGS) com teores de projeto determinados a partir do método de dosagem Marshall, seguindo DNER-ME 043/95 - ME [22]. Com volume de vazios de 5,5\% \pm 0,5\% e dimensões de $100 \mathrm{~mm}$ de diâmetro por $170 \mathrm{~mm}$ de altura, após a moldagem, os corpos de prova foram retificados em suas extremidades e lixados para melhor aderência à colagem, passando a medir 100x130 mm.

Para fixação da amostra junto às placas de colagem, que foram previamente lixadas também, a fim de garantir maior aderência entre sua superfície e a cola, utilizou-se de cola epóxi de baixa viscosidade e alta resistência. Seu tempo de secagem varia conforme o fabricante, neste caso, de 16 a 20 horas. A temperatura de condicionamento das amostras foi $19^{\circ} \mathrm{C}$, que varia de acordo com o PG (Perfomance Grade) do ligante asfáltico utilizado na mistura, segundo especificado pela norma AASHTO TP 107-14 [19].

O processo de instalação do sistema se deu, primeiramente, pelo encaixe da placa de suporte inferior à mesa da prensa. Acima dessa placa, a amostra, já colada, é posicionada, fixada por parafusos e condicionada na temperatura de ensaio. Em seguida, coloca-se a placa de suporte superior, também fixada por parafusos, que garante a conexão entre o sistema de rotulagem e todo sistema de acoplagem à prensa UTM-25. A Figura 7 demonstra o sistema completo de ensaio de Fadiga por Tração-Compressão Direta (Uniaxial) montado e apto para execução do ensaio.
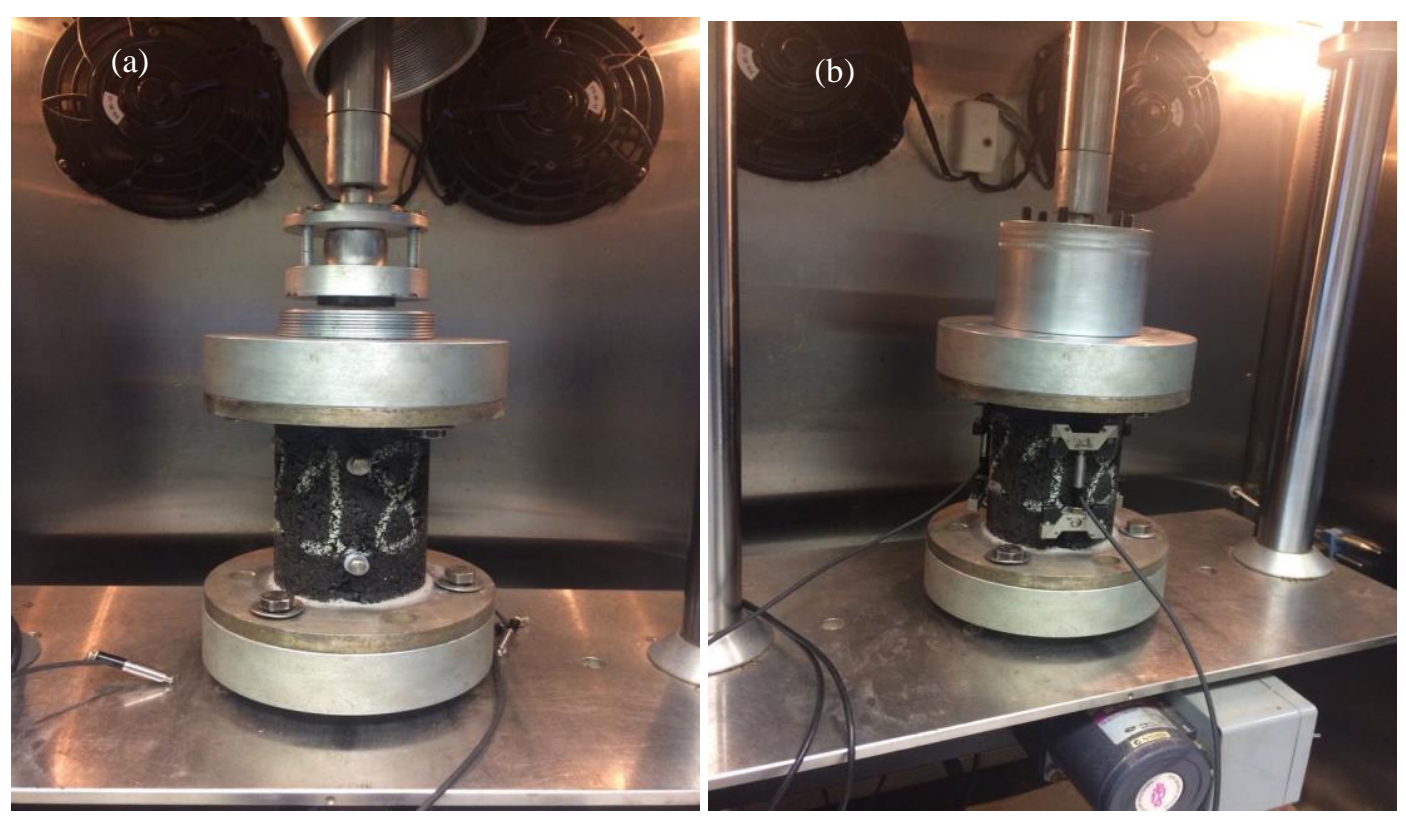

Figura 7: Sistema de ensaio de Fadiga por Tração-Compressão Direta (Uniaxial) da UFSM (a) durante montagem do aparato e (b) apto para realização do teste. 
O ensaio consiste em aplicar nos corpos de prova uma deformação cíclica senoidal, de amplitude constante, até que a amostra entre em colapso, ou seja depois da evolução suficiente de dano à fadiga. Os testes foram conduzidos a uma frequência de $10 \mathrm{~Hz}$ e com uma variação da amplitude de deformação em quatro níveis, sendo um nível por amostra, buscando que os níveis de deformação fiquem dentro da faixa de ruptura de 1000 ciclos a 100000 ciclos. A queda do ângulo de fase é utilizada para determinar o momento da falha da amostra (critério de ruptura), de acordo com REESE [23].

A execução do ensaio consiste em duas fases: primeiramente, aplica-se, utilizando a mesma frequência do ensaio de fadiga, um pequeno carregamento na amostra (provocando deformação de cerca de 50 a 75 $\mu \mathrm{m}$ on-specimen, medido a partir dos LVDTs acoplados à amostra) para determinar o módulo complexo (esse pequeno ensaio de módulo precedendo o ensaio de fadiga é conhecido como fingerprint). Em seguida, a amostra é submetida ao ensaio de fadiga em que o atuador é programado para chegar a um deslocamento de pico constante em cada ciclo de carga até que se atinja a ruptura.

As medidas dos deslocamentos realizadas durante a execução do ensaio, pelo LVDT do atuador e dos três transdutores acoplados à amostra, estão representadas nas Figuras 8 e 9 em função de um intervalo de tempo amostrado, bem como os valores de carregamento, na Figura 10.

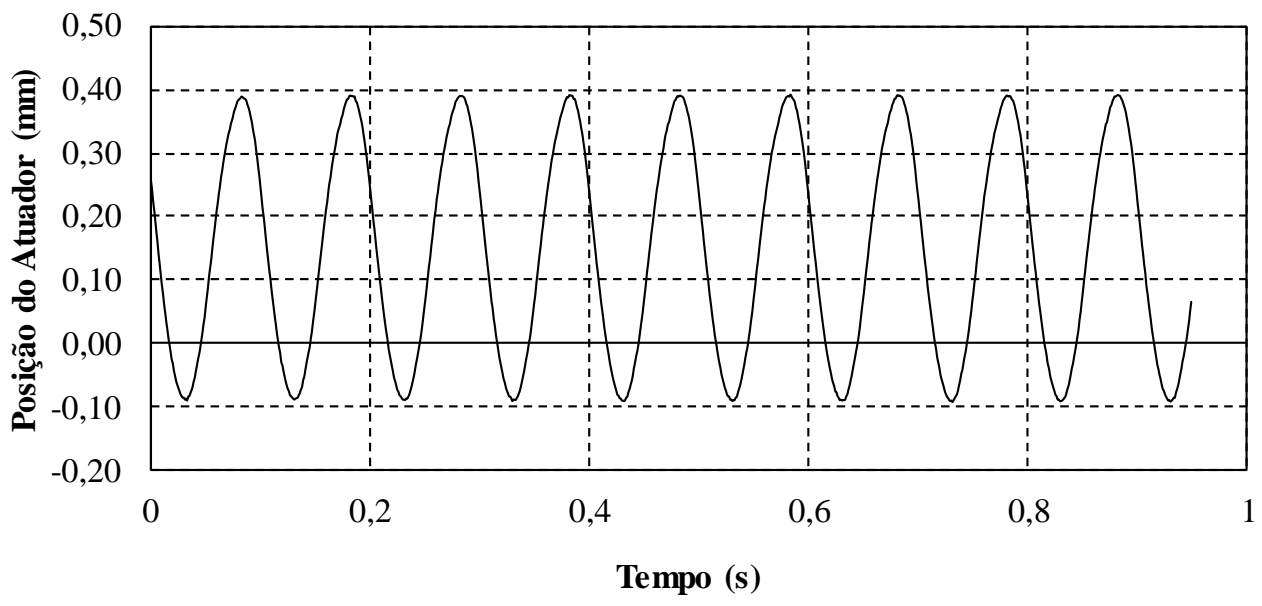

Figura 8: Leituras do LVDT do atuador durante execução do ensaio.

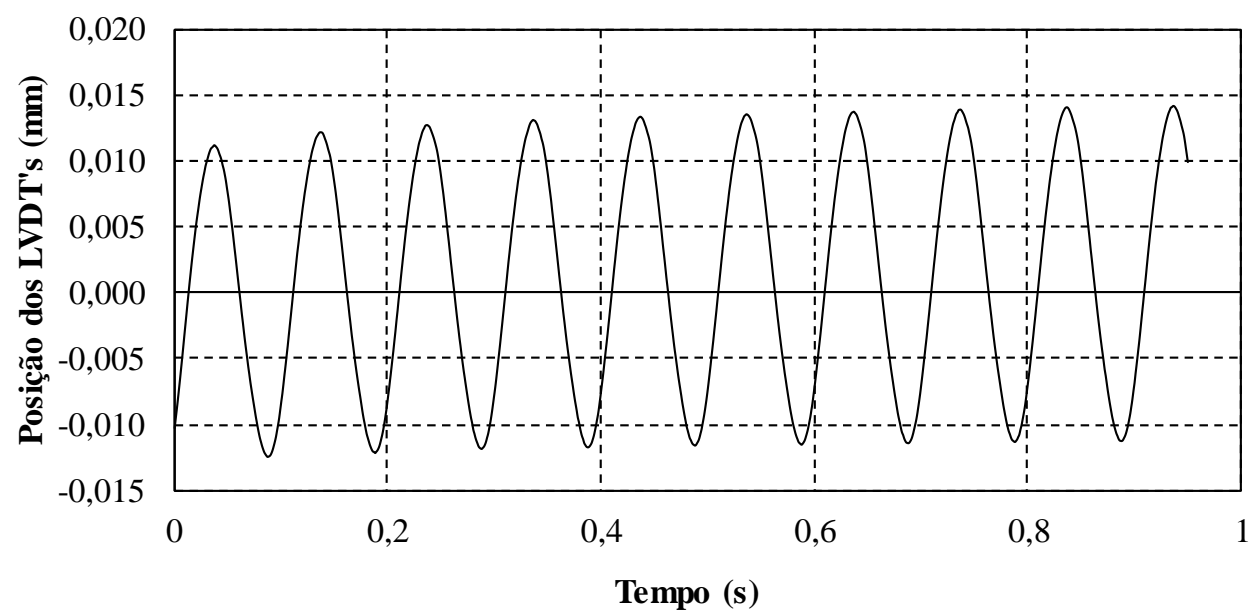

Figura 9: Leituras dos LVDTs acoplados à amostra durante execução do ensaio. 


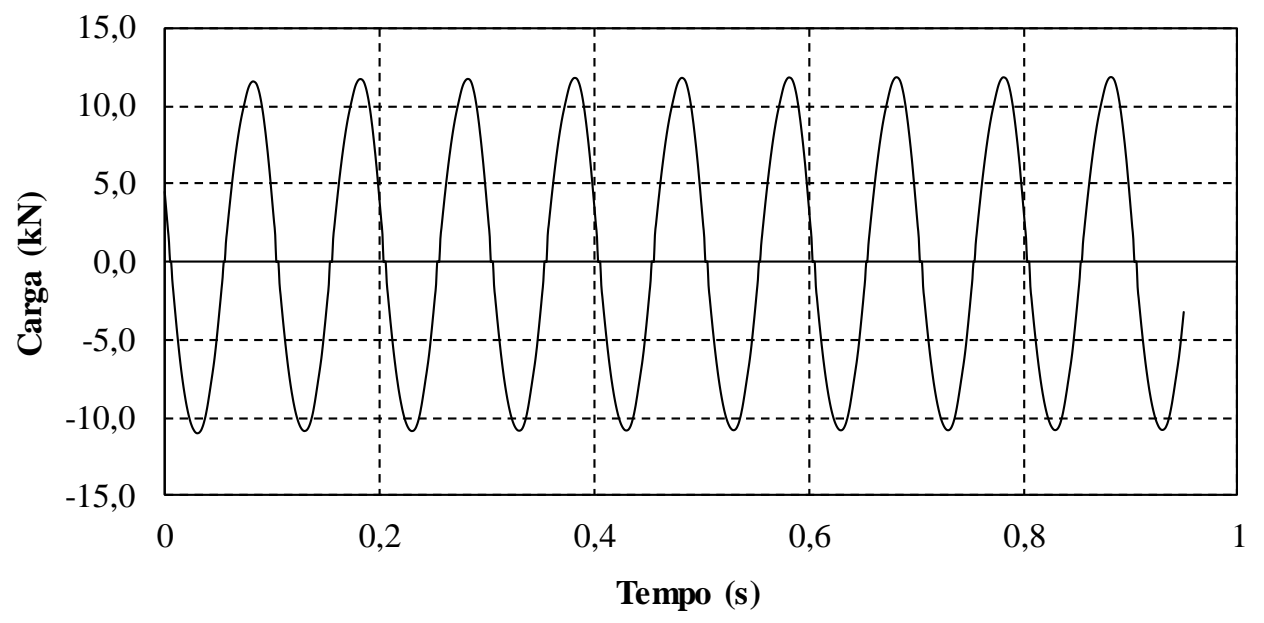

Figura 10: Leituras dos carregamentos durante execução do ensaio.

\section{REPRESENTAÇÃO DOS DADOS DE ENSAIO}

Os resultados obtidos nos ensaios de fadiga por compressão diametral à tensão controlada, mais utilizados para determinação da vida de fadiga no Brasil, são bastante simples tanto na execução quanto na preparação das amostras. As amostras podem ser preparadas com o uso do soquete Marshall ou extraídas de placas ou da pista. Em contraponto, são ensaios demorados e que demandam grande número de amostras (15, aproximadamente). Os resultados são comumente representados através da curva de Wöhler, que relaciona o desempenho à fadiga de um material e um tipo de solicitação aplicada (tensão de tração, diferença de tensões e/ou deformação específica inicial). Entretanto, devido às propriedades viscoelásticas das misturas asfálticas, não é possível realmente estimar seu comportamento sob diferentes condições de carregamento [11, 24].

Através dos testes do ensaio de Fadiga por Tração-compressão Direta (Uniaxial), também é possível construir a curva de Wöhler, apresentada na Figura 11, pela relação do número de ciclos até a ruptura versus deformação específica média de cada uma das amostras ensaiadas.

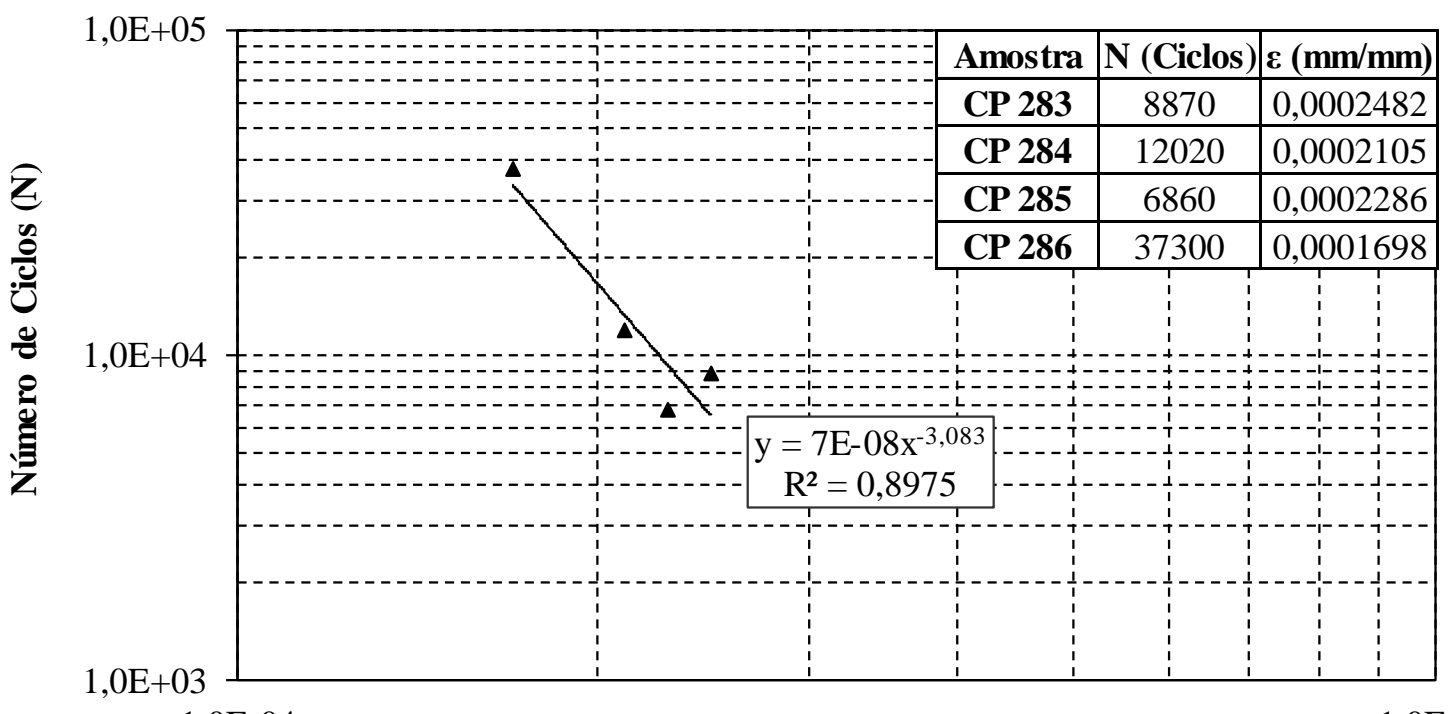

$1,0 \mathrm{E}-04$

$1,0 \mathrm{E}-03$

Deformação específica média $(\mathrm{mm} / \mathrm{mm})$

Figura 11: Relação entre desempenho de fadiga à tração e deformação específica média para diferentes ensaios de Fadiga por Tração-Compressão Direta (Uniaxial).

Normalmente, no ensaio de fadiga por compressão diametral à tensão controlada, utiliza-se a defor- 
mação específica inicial, entretanto, no ensaio de Fadiga por Tração-compressão Direta (Uniaxial), devido ao monitoramento das deformações ao longo do ensaio, é possível se obter a deformação média para o mesmo tipo de carregamento. No ensaio de tensão controlada, a deformação é crescente ao longo do ensaio e a utilização da deformação específica inicial leva a um erro na interpretação.

No caso deste trabalho, o ensaio foi realizado através do controle de deslocamento do atuador, que gera a deformação desejada nos ciclos iniciais de ensaio. Durante o ensaio são coletados, além da deformação, a carga, o ângulo de fase e o módulo dinâmico, e então, para cada amostra, é possível a construção da Curva Característica de Dano. Com isso, foi possível plotar as curvas das Figuras 12 e 13 que relacionam a variação do Módulo Dinâmico $\left(\left|E^{*}\right|\right)$ e do Ângulo de Fase $(\delta)$, importantes indicadores das propriedades elásticas e viscoelásticas do material [25], e o número de ciclos para os quatro níveis de deformação ensaiados.

Conforme MAGIAFICO [26], durante o ensaio, as amostras sofreram deterioração progressiva, cujo fenômeno, juntamente com a falha prematura, é considerado efeito das cargas repetidas. Especificamente, à medida em que o número de ciclos aumenta, o valor do módulo complexo diminui enquanto o valor do ângulo de fase aumenta.

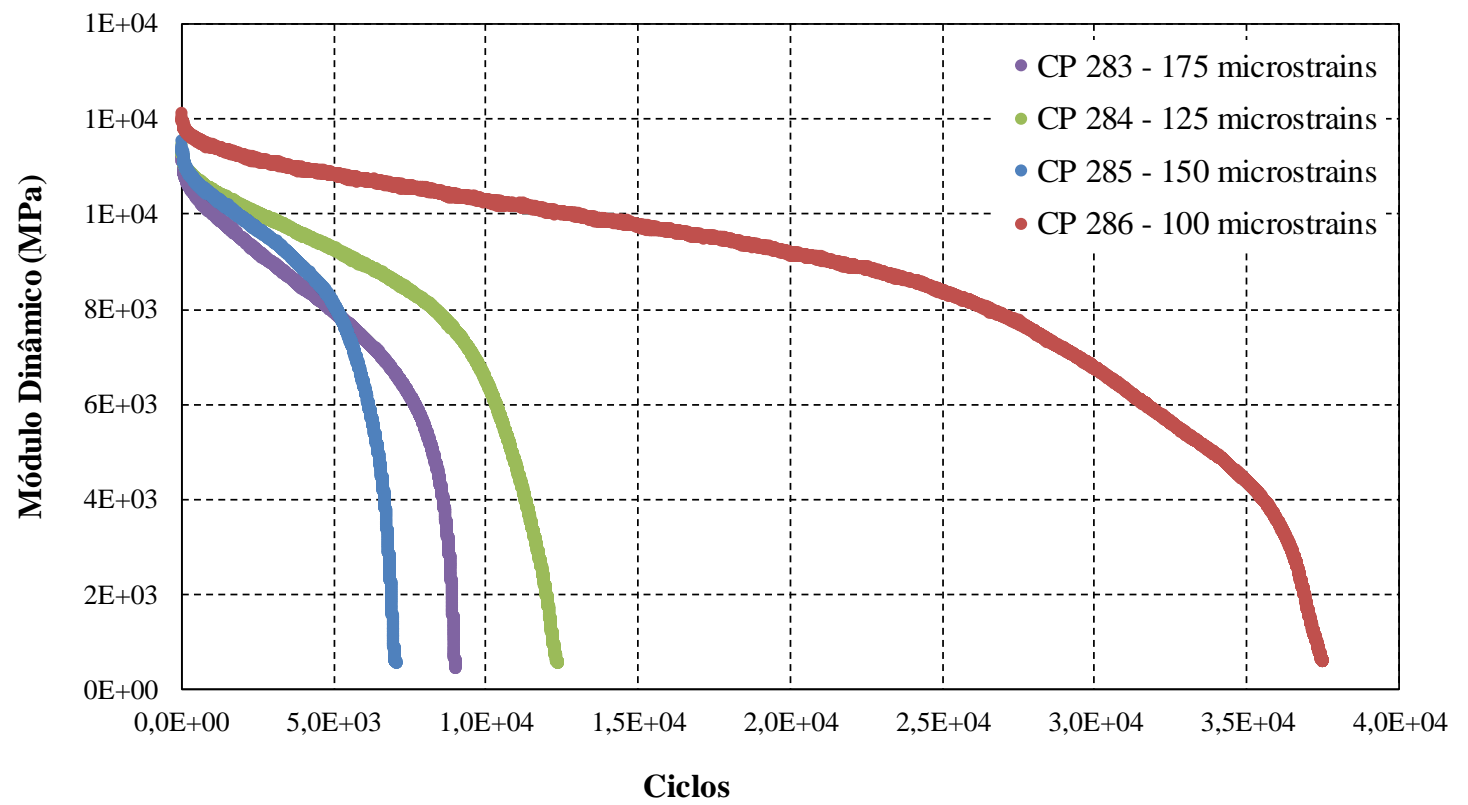

Figura 12: Relação entre o Módulo Dinâmico medido ao longo dos ciclos para diferentes ensaios de Fadiga por TraçãoCompressão Direta (Uniaxial). 


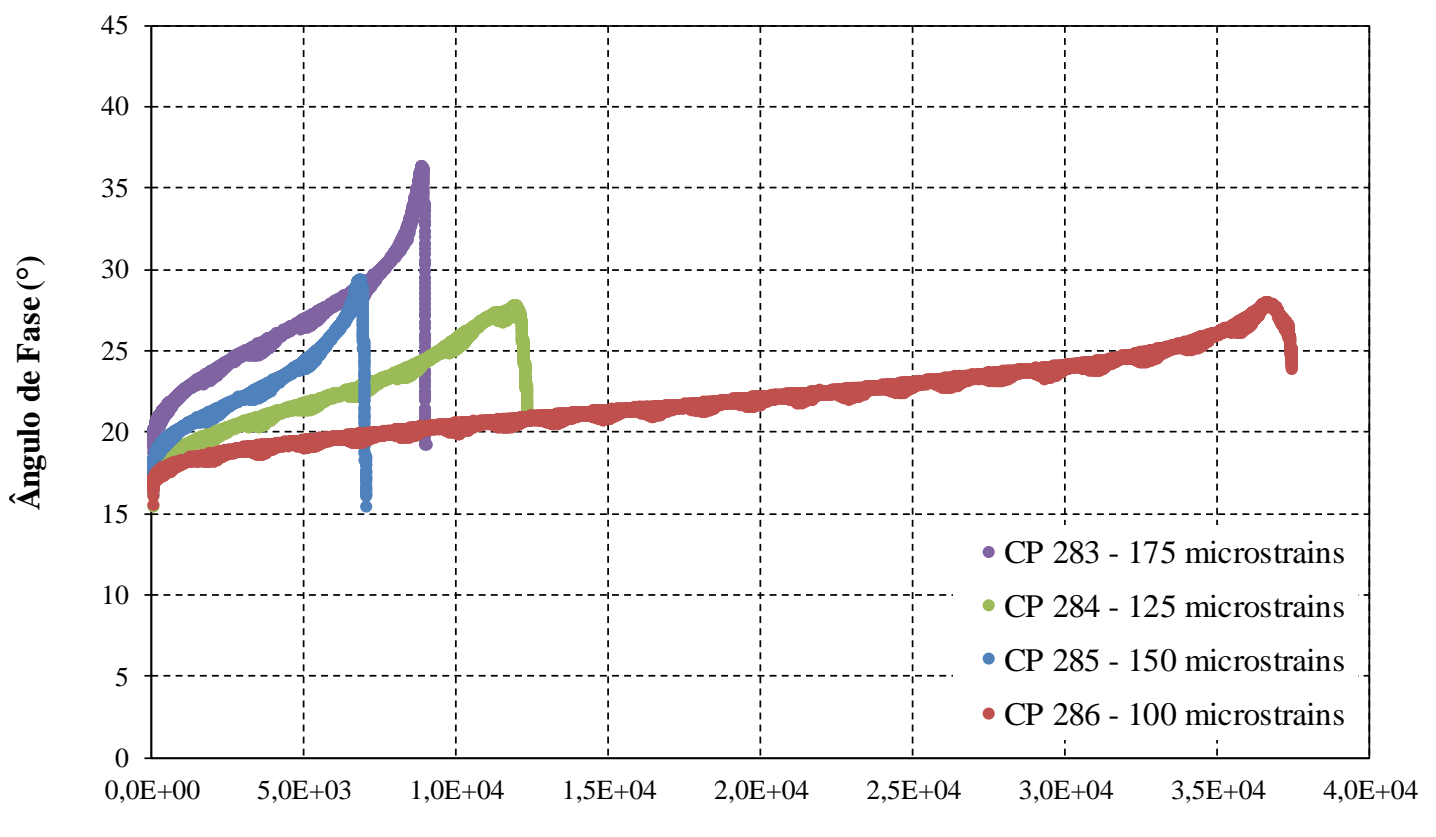

Ciclos

Figura 13: Relação entre o Ângulo de Fase medido ao longo dos ciclos para diferentes ensaios de Fadiga por TraçãoCompressão Direta (Uniaxial).

KIM [27] comenta que o S-VECD foi concebido para utilização em laboratórios como um procedimento de caracterização de danos com economia de tempo e, como os ensaios cíclicos são utilizados para calibrar o modelo, podem ser obtidos os critérios de fadiga. Sendo que uma das principais diferenças do ensaio clássico (compressão diametral) para determinação da vida de fadiga para o S-VECD é a interpretação teórica mais consistente, baseada na mecânica do dano contínuo viscoelástico.

Para utilização desse modelo, dois parâmetros principais devem ser quantificados: a pseudo-rigidez (C), também chamada de integridade do material, e o dano (S). A relação entre estes parâmetros é única para um dado material, podendo ser considerada como uma propriedade fundamental, de acordo com NASCIMENTO et al. [18]. Os autores comentam que uma das principais vantagens desse modelo é a obtenção da propriedade de dano das misturas, independentemente das condições de ensaio (temperatura, amplitude, controle de tensão ou deformação). Assim, ensaios realizados em uma condição específica, permitem a obtenção do comportamento do material em diversas outras condições, reduzindo o tempo de ensaios laboratoriais. Ainda, esse modelo pode ser utilizado de várias formas, porém duas valem destaque: a possibilidade de obtenção de curvas de fadiga em diferentes condições daquela ensaiada; e, propiciar informações necessárias à análise mecânica do pavimento a partir do dano contínuo viscoelástico.

Esta relação C versus S, representada a Figura 14, é independente de muitos dos fatores que afetam o desempenho à fadiga, como temperatura e frequência e, portanto, pode descrever o comportamento de dano a partir da realização de uma quantidade relativamente pequena de ensaios de laboratório. 


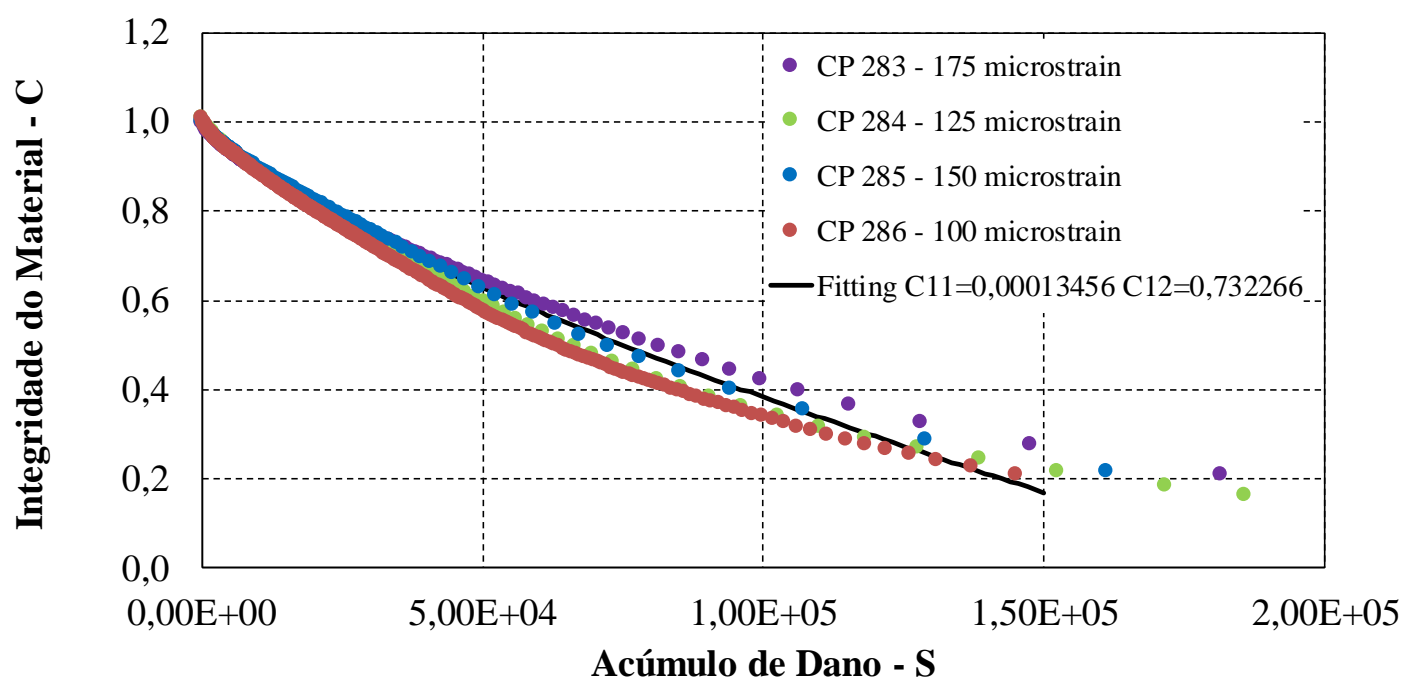

Figura 14: Curva Característica de Dano para diferentes amplitudes de deformação.

Na Figura 14 é possível observar verificação de uma das hipóteses do modelo VECD: as propriedades de dano da mistura (relação entre C e S) são independentes da condição do teste, mostrando dessa forma que ensaios realizados em condições específicas permitem a obtenção do comportamento do material em diversas outras condições de tempo ou temperatura. Para a mistura em estudo, gerou-se um ajuste (fitting) das quatro amostras, por meio de uma função potência. Através deste ajuste e da Curva Característica de Dano, obtêmse os principais parâmetros do S-VECD, conforme Tabela 1.

Tabela 1: Parâmetros obtidos pelo modelo S-VECD.

\begin{tabular}{l|l|l}
\hline \multicolumn{3}{l}{ MISTURA FAIXA C 50/70 } \\
\hline \multirow{3}{*}{ FITTING } & $\mathrm{C} 11$ & 0,00013456 \\
\cline { 2 - 3 } & $\mathrm{C} 12$ & 0,73226 \\
\hline \multirow{3}{*}{ GR } & $\mathrm{Y}$ & 2000000 \\
\cline { 2 - 3 } & $\Delta$ & $-1,09$ \\
\hline \multirow{3}{*}{ WLF } & $\mathrm{C} 1$ & 36,785 \\
\hline \multirow{3}{*}{ MISTURA } & $\mathrm{C} 2$ & 259,16 \\
\cline { 2 - 3 } & $\alpha$ & 3,1976 \\
\cline { 2 - 3 } & $\left|E^{*}\right|_{\text {LVE }}(\mathrm{MPa})$ & 16381 \\
\hline
\end{tabular}

O C11 e C12 são os coeficientes da curva C versus $\mathrm{S}$ gerados pelo fitting, o Y e o $\Delta$ são os coeficientes do critério de ruptura Gr versus Nf (Gr é a taxa de variação da média da energia de pseudo-deformação com respeito ao número de ciclos). $\mathrm{O} \alpha$ é a taxa de evolução do dano e $\left|\mathrm{E}^{*}\right|_{\text {LVE }}$ é o módulo dinâmico viscoelástico linear nas condições de temperatura e frequência do ensaio. Já os parâmetros WLF (C1 e C2) são dados obtidos a partir dos resultados do ensaio de módulo dinâmico. De posse desses parâmetros, é possível então a utilização de soluções analíticas e sistemas computacionais para a determinação da vida de fadiga (Nf) de estruturas de pavimentos considerando a velocidade do tráfego e as variações sazonais e diárias de temperatura.

\section{CONCLUSÃO}

O presente artigo se propôs a discutir as propriedades de fadiga medidas em laboratório a partir do desenvolvimento de um aparato acoplado à prensa UTM-25 para ensaios de Fadiga por Tração-compressão Direta (Uniaxial). O sistema mecânico desenvolvido apresentou-se bastante adequado às necessidades, sendo possí- 
vel a perfeita colagem das placas na amostra e sua correta centralização com do sistema de rotulagem desenvolvido.

A partir do controle das respostas mecânicas da prensa e do material ensaiado, não foram constatadas disfunções do sistema que acarretassem possíveis alterações das leituras de ensaio, evidenciando a eficácia das peças confeccionadas. Já, com os dados obtidos, e baseando-se no ferramental do modelo S-VECD, foi possível estabelecer curvas típicas de dano (C versus $\mathrm{S}$ ) bastante satisfatórias e que, independentemente da condição do teste, determina-se um conjunto de propriedades e parâmetros que permitem a obtenção do comportamento em diversas outras condições de tempo de carregamento (frequência) ou temperatura.

Além de contribuir com a disseminação de um novo ensaio, mais prático e eficiente, e com a importante avaliação do dano viscoelásico por fadiga, espera-se que, em breve, o novo método de dimensionamento em vigor possa assumir tais teorias, fornecendo mais ferramentas aos projetistas e possibilitando projetos mais assertivos e seguros.

\section{AGRADECIMENTOS}

Ao CNPq e à CAPES pelas bolsas de ofertadas; à ANP/Petrobras pelo fomento à pesquisa no âmbito da Rede Temática de Asfalto; e ao Cenpes e à UFC pela disponibilidade e contribuição com o trabalho.

\section{BIBLIOGRAFIA}

[1] BERNUCCI, B.B., MOTTA, L.M.G., CERATTI, J.A.P., et al., "Pavimentação asfáltica Formação básica para engenheiros", 3 ed., Rio de Janeiro, PETROBRAS, Associação brasileira das empresas distribuidoras de asfalto, 2008.

[2] BASTOS, J.B.S., BORGES, R.L., SOARES, J.B., et al., "Avaliação em laboratório e em campo da deformação permanente de pavimentos asfálticos do Ceará e de São Paulo", Revista Transportes, v. 23, n. 3, pp. 44-55, Jul. 2015.

[3] NASCIMENTO, L.A.H., Implementation and Validation of the Viscoelastic Continuum Damage Theory for Asphalt Mixture and Pavement Analysis in Brazil, Ph.D Dissertation, NCSU, Raleigh, NC, USA, 2015.

[4] PORTER, O.J., "Foundations for Flexible Pavements", Highway Research Board, Proceedings of the Twenty-second TRB Annual Meeting, Washington, D.C., v. 22, pp. 100-136, 1942.

[5] NIJBOER, L.W., VAN DER POEL, C., "A Study of Vibration Phenomena in Asphalt Road Construction”, Assoc Asphalt Paving Technol Proc., v. 22, pp. 197-231, 1953.

[6] HVEEM, F.N., "Pavement Deflections and Fatigue Failures", Highway Research Board, Washington, D.C., bul. 114, pp. 43-87, 1955.

[7] MOAVENZADEH, F., "Damage and Distress in Highway Pavements", In: Highway Research Board, Workshop on Structural Design of Asphalt Pavement Systems, The University of Texas, Austin, TX, USA, pp. 114-133, 1971.

[8] PREUSSLER, E.S., PINTO, S., MEDINA, J., "Determinação da vida de fadiga de concretos asfálticos brasileiros e aplicação no dimensionamento de reforço de pavimentos", In: Anais da $16^{a}$ Reunião Anual de Pavimentação da ABPv, Vol 2, pp. 67-122, Recife, PE, 1981.

[9] CERATTI, J.A.P., Estudo do Comportamento a Fadiga de Solos Estabilizados com Cimento para Utilização em Pavimentos, Tese de D.Sc., COPPE/UFRJ, Rio de Janeiro, RJ, Brasil, 1991.

[10] PINTO, S., Estudo do Comportamento à Fadiga de Misturas Betuminosas e Aplicação na Avaliação Estrutural de Pavimentos, Tese de D.Sc., COPPE/UFRJ, Rio de Janeiro, RJ, Brasil, 1991.

[11] BABADOPOLUS, L.F.A.L., SOARES, J.B., CASTELO BRANCO, V.T.F., "Interpreting fatigue tests in hot mix asphalt (HMA) using concepts from viscoelasticity and damage mechanics", Revista Transportes, v. 23 , n. 2, pp. 85-94, 2015.

[12] DI BENEDETTO, H., CORTÉ, J., Matériaux routiers bitumineux 2: constitution et propriétés thermomécaniques des mélanges bitumineux, vol. 2, Edit. Hermés Lavoisier, Paris, França, 2005.

[13] AMERICAN ASSOCIATION OF STATE HIGHWAY AND TRANSPORTATION, AASHTO T32107, "Determining the Fatigue Life of Compacted Hot-Mix Asphalt (HMA) Subjected to Repeated Flexural Bending", Washington, DC, 2007. 
[14] AMERICAN SOCIETY FOR TESTING AND MATERIALS, ASTM D7460-08, "Standard Test Method for Determining Fatigue of Compacted Asphalt Concrete Subjected to Repeated Flexural Bending", Philadelphia, USA, 2008.

[15] DI BENEDETTO, H., LA ROCHE, D., BAAJ, H., PRONK, A., et al., "Fatigue of bituminous mixtures", Materials and Structures, v. 37, pp. 202-216, Abril, 2004.

[16] UNDERWOOD, B.S., BAEK, C., KIM, Y.R., "Simplified viscoelastic continuum damage model as platform for asphalt concrete fatigue analysis", Transportation Research Record: Journal of the Transportation Research Board, 2296-1, pp. 36-45, 2012.

[17] MARTINS, A.T., Contribuição para a validação do ensaio de resistência ao dano por fadiga para ligantes asfálticos, Dissertação de M.Sc., COPPE/UFRJ, Rio de Janeiro, RJ, Brasil, 2014.

[18] NASCIMENTO, L.A.H., ROCHA, S.M.N., NASCIMENTO, C.E.H., et al., "Uso da mecânica do dano contínuo na caracterização de misturas asfálticas brasileiras", In: Anais do $21^{\circ}$ Encontro de Asfalto, Instituto Brasileiro do Petróleo, Rio de Janeiro, RJ, Maio, 2014.

[19] AMERICAN ASSOCIATION OF STATE HIGHWAY AND TRANSPORTATION, AASHTO TP10714, "Determining the Damage Characteristic Curve of Asphalt Concrete from Direct Tension Cyclic Fatigue", American Association of State Highway and Transportation Officials, Washington, D. C. Tests, 2014. [20] BOEIRA, F. D., Estudo do Comportamento Mecânico de Misturas Asfálticas com Ligantes Modificados, Tese de D.Sc., UFSM, Santa Maria, RS, Brasil, 2018, no prelo.

[21] DEPARTAMENTO NACIONAL DE INFRAESTRUTURA E TRANSPORTES - DNIT, "DNIT 031/2006 - ES: Pavimentos flexíveis - Concreto asfáltico - Especificação de serviço", Rio de Janeiro, 2006.

[22] DEPARTAMENTO NACIONAL DE ESTRADAS DE RODAGEM - DNER, "DNER 043/95 - ME: Misturas betuminosas a quente: ensaio Marshall para misturas betuminosas", Rio de Janeiro, 1995.

[23] REESE, R., "Properties of Aged Asphalt Binder Related to Asphalt Concrete Fatigue Life", Journal of the Association of Asphalt Paving Technologists, AAPT, v. 66, pp. 604-632, 1997.

[24] SPECHT, L.P., Avaliação de Misturas Asfálticas com Incorporação de Borracha Reciclada de Pneus, Tese de D.Sc., UFRGS, Porto Alegre, RS, Brasil, 2004.

[25] SPECHT, L. P., BABADOPULOS, L. F. A., BENEDETTO, H., et al., "Application of the theory of viscoelasticity to evaluate the resilient modulus test in asphalt mixes", Construction and Building Materials, v. 149, pp. 648-658, 2017.

[26] MANGIAFICO, S., Linear viscoelastic properties and fatigue of bituminous mixtures produced with Reclaimed Asphalt Pavement and corresponding binder blends. Tese de D.Sc., l'École Nationale des Travaux Publics de l'État, Lyon, França, 2014.

[27] KIM, Y.R., Modeling of Asphalt Concrete, 1 ed., American Society of Civil Engineers, McGraw-Hill Construction, 2009. 